\title{
MORE ACTIVE AND SULFUR RESISTANT BIMETALLIC Pd-Ni CATALYSTS
}

\author{
Carolina Bettia, Nicolás Carrara ${ }^{\mathrm{a}}$, Juan Badano ${ }^{\mathrm{a}}$, Cecilia Lederhos ${ }^{\mathrm{a}}$, Carlos Vera ${ }^{\mathrm{a}, \mathrm{b}}$ and Mónica Quiroga ${ }^{\mathrm{a}, \mathrm{b}, *}$ \\ ${ }^{a}$ Instituto de Investigaciones en Catálisis y Petroquímica, INCAPE (FIQ-UNL, CONICET), Colectora Ruta Nac. N 168 Km 0 , \\ Paraje El Pozo, 3000 Santa Fe, Argentina \\ 'Departamento de Química, Facultad de Ingeniería Química, Universidad Nacional del Litoral, Santiago del Estero 2829, S3000AOJ \\ Santa Fe, Argentina
}

Recebido em 07/07/2017; aceito em 02/10/2017; publicado na web em 13/11/2017

\begin{abstract}
The influence of the kind of metal precursor and the sequence of impregnation on the properties of Pd-Ni catalysts was evaluated during the test reaction of selective hydrogenation of styrene to ethylbenzene by means of physicochemical characterization. The focus was put on the final hydrogenating activity and the resistance to deactivation by sulfided compounds (thiophene). The used techniques of characterization were ICP, XPS, XDR, TPR, CO chemisorption and TEM. XPS results indicated the presence of different $\mathrm{Pd}$ species: $\mathrm{Pd}^{\delta-}, \mathrm{Pd}^{0}$ and $\mathrm{Pd}^{\delta+}$. In the case of the $\mathrm{Ni}$ containing catalysts, $\mathrm{Ni}^{0}$ and $\mathrm{NiO}$ species were also detected. These palladium and nickel species would be responsables of the variation of activity and sulfurresistance of the catalysts. NiClPd catalysts had a higher resistance to deactivation by sulfur poisoning. This was associated to a higher concentration of $\mathrm{Pd}^{\eta+} \mathrm{Cl}_{\mathrm{x}} \mathrm{O}_{\mathrm{y}}$ species that would prevent the adsorption of thiophene by both steric and electronic effects. It could also be due to the lower concentration of $\mathrm{Pd}^{0}$ and $\mathrm{Ni}^{0}$ on these catalysts, as compared to those shown by the $\mathrm{PdNiCl}$ catalysts. Both the $\mathrm{Pd}^{0}$ and $\mathrm{Ni}^{0}$ species are more prone to poisoning because of their higher electronic availability.
\end{abstract}

Keywords: selective hydrogenation; bimetallic catalysts; sulfur resistance; palladium; nickel.

\section{INTRODUCTION}

Many petrochemical processes and applications in biotechnology, pharmacy and agrochemicals are based on the catalytic heterogeneous hydrogenation of hydrocarbons. The main objectives of these processes are to get the highest possible yields in conditions of reasonably mild pressure and temperature, and at the lowest cost.

Petroleum hydrocarbon mixtures contain unsaturated compounds and many aromatic compounds. For this reason it is important that the reaction may be selective to the desired products. Particularly the heterogeneous reactions of selective hydrogenation of vinylic compounds that keep the aromatic nucleus intact are of great interest and usefulness in the petrochemical industry. A clear example are the pyrolysis gasolines that are a low quality subproduct of cracking processes for olefin production. ${ }^{1,2}$ Selective hydrogenation permits obtaining processed gasoline that meets the quality and octane conditions for its addition to the gasoline pool. Besides aromatic compounds like Benzene, Toluene and Xylene (BTX) can be extracted and used for other petrochemical uses.

The hydrogenation of styrene to ethylbenzene is considered as a model for the study of the purification of pyrolysis gasoline because styrene is the most refractory compound for hydrogenation. Both $\mathrm{Pd}$ and Ni catalysts are used for styrene hydrogenation. ${ }^{3,4}$ The main problem of the PyGas streams is that they contain high amount of sulfided compounds, usually between 300 and $2000 \mathrm{ppm}^{1,3,5}$ that poison the catalysts. Thiophene is one of the main sulfided compounds causing deactivation of the catalysts by poisoning. In a previous work with monomethalic catalysts the effect of chlorine for the sulfurresistance was studied. In Badano et al., ${ }^{6}$ it was found that chloride complex species $\left(\mathrm{Pd}_{\mathrm{x}}{ }^{\delta} \mathrm{O}_{\mathrm{y}} \mathrm{Cl}_{\mathrm{z}}\right.$ and the $\mathrm{Pt}_{\mathrm{x}}{ }^{\delta+} \mathrm{O}_{\mathrm{y}} \mathrm{Cl}_{\mathrm{z}}$, with $\delta<2$ ) present in the surface could hinder the adsorption of poisons via a steric factor (big size of chlorine ligands) or an electronic one (high electronegativity). Besides, bimetallic catalysts are potentially

*e-mail: mquiroga@fiq.unl.edu.ar thioresistant systems. In a previous work our group studied Pt-Ni and Pt-W catalysts, and reported electronic and steric effects that improved the activity or the sulfur resistance. ${ }^{7,8}$

The objectives of this work were three: (i) the synthesis of bimetallic Pd-Ni catalysts varying the order of impregnation of the metals and the kind of precursor; chlorided and nitrogenated precursors were used; (ii) the catalytic evaluation of these catalysts; (iii) the assessment of the resistance of the catalysts to deactivation by sulfur poisoning. Four bimetallic catalysts were synthesized: PdNiN, $\mathrm{NiNPd}, \mathrm{PdNiCl}$ and NiClPd. Results of activity and thioresistance were compared to the properties of a monometallic Pd catalyst.

\section{EXPERIMENTAL}

\section{Catalysts preparation}

Bimetallic catalysts were prepared by successive impregnation of the metal precursors in solution. The used support was $\gamma-\mathrm{Al}_{2} \mathrm{O}_{3}$ Ketjen CK 300. This was previously calcined in order to stabilize its surface area $\left(\mathrm{S}_{\mathrm{BET}}: 224 \mathrm{~m}^{2} \mathrm{~g}^{-1}\right)$. For the incorporation of the metals to the support the technique of incipient wetness impregnation was used.

Impregnating solutions with dissolved $\mathrm{PdCl}_{2}, \mathrm{NiCl}_{2}$ or $\mathrm{Ni}\left(\mathrm{NO}_{3}\right)_{2} \cdot 6 \mathrm{H}_{2} \mathrm{O}$ were used to obtain monometallic catalysts of $\mathrm{Pd}$, $\mathrm{NiCl}$ and $\mathrm{NiN}$. Monometallic catalysts were dried with $24 \mathrm{~h}$ in a stove at $373 \mathrm{~K}$, then they were calcined in dried air for $3 \mathrm{~h}$ at $823 \mathrm{~K}$ and finally they were reduced for $1 \mathrm{~h}$ at $673 \mathrm{~K}$ in a hydrogen flow of $110 \mathrm{~mL} \mathrm{~min}^{-1}$. During the impregnation of the second metal, an acidified solution of $\mathrm{PdCl}_{2}$ was impregnated over the monometallic catalysts of $\mathrm{NiN}$ and $\mathrm{NiCl}$, for obtaining the bimetallic catalysts NiNPd and NiClPd respectively. Similarly, acidified solutions of $\mathrm{NiCl}_{2}$ and $\mathrm{Ni}\left(\mathrm{NO}_{3}\right)_{2} \cdot 6 \mathrm{H}_{2} \mathrm{O}$ were impregnated over Pd monometallic catalysts to obtain the $\mathrm{PdNiCl}$ and $\mathrm{PdNiN}$ catalysts, respectively. The resulting bimetallic catalysts were dried for $24 \mathrm{~h}$ in a stove at $373 \mathrm{~K}$, calcined for $3 \mathrm{~h}$ at $823 \mathrm{~K}$ and reduce for $1 \mathrm{~h}$ at 673 in a hydrogen stream of $110 \mathrm{~mL} \mathrm{~min}^{-1}$ before the reaction test. 


\section{Catalysts characterization}

The mass concentration of $\mathrm{Pd}$ and $\mathrm{Ni}$ in the final catalysts was determined by plasma induction atomic emission spectroscopy (ICPOES). The equipment used was a Perkin Elmer 2100 and the samples had to be previously digested in diluted sulfuric acid for the analysis.

The electronic state of the Pd and Ni surface species and their atomic ratios were determined by means of X-ray photoelectron spectroscopy (XPS). XPS spectra were recorded in a Multitecnica UniSpecs equipment. It had an XR50 model X-ray dual Mg/Al source and a hemispheric Phoibos 150 analyzer working in fixed analyzer transmission mode (FAT). The spectra were obtained with an energy pass of $30 \mathrm{eV}$ and a $\mathrm{Mg}$ anode operated at $200 \mathrm{~W}$. The pressure during the measurements was lower than $210^{-8} \mathrm{mBar}$. The samples were previously reduced in situ in the reaction chamber of the instrument, with a stream of $\mathrm{H}_{2}$ :Ar at $673 \mathrm{~K}$ for $10 \mathrm{~min}$. The reference binding energy used as a reference was $\mathrm{Al} 2 \mathrm{p}$ at $74.1 \mathrm{eV}$.

$\mathrm{X}$-ray diffraction (XRD) spectra of the powdered samples were obtained in a Shimadzu XD-1 instrument using $\mathrm{CuK}_{\alpha}$ radiation $(\lambda=1.5405 \AA)$ filtered with $\mathrm{Ni}$, in the $15^{\circ}<2 \theta<85^{\circ}$ range and at a scan speed of $1^{\circ} \min ^{-1}$. The samples were powdered and reduced ex situ under a hydrogen flow. Then they were cooled down to room temperature in nitrogen flow and put into the chamber of the equipment to record the spectrum.

The study of the reducibility of the surface species was performed by temperature programmed reduction (TPR) in a Micromeritics Auto Chem II apparatus equipped with a thermal conductivity detector. A cold water trap was placed before the thermal detector to condense water. Before the TPR tests the samples were pretreated in situ in an air stream at $773 \mathrm{~K}$ for $30 \mathrm{~min}$. After that the samples were cooled up to $308 \mathrm{~K}$ in an Ar stream (AGA purity $99.99 \%$ ). Then the temperature was increased up to $1173 \mathrm{~K}$ at $10 \mathrm{~K} \mathrm{~min}^{-1}$ in a gas flow $(5 \%(\mathrm{v} / \mathrm{v})$ hydrogen in argon) at a total flow rate of $40 \mathrm{~mL} \mathrm{~min}^{-1}$.

$\mathrm{CO}$ chemisorption experiments were performed in a chemisorption equipment designed ad-hoc. The catalyst was placed in a quartz reactor and first over reduced in situ in a hydrogen stream $(673 \mathrm{~K}, 1 \mathrm{~h}$, $60 \mathrm{~cm}^{3} \mathrm{~min}^{-1}$ ). Then the carrier was switched to $\mathrm{N}_{2}$ and the adsorbed hydrogen was desorbed $\left(673 \mathrm{~K}, 60 \mathrm{~cm}^{3} \mathrm{~min}^{-1}\right)$ for $1 \mathrm{~h}$; then the cell was cooled down up to room temperature. Then $0.42 \mathrm{~cm}^{3}$ pulses of diluted $\mathrm{CO}\left(3.04 \% \mathrm{CO}\right.$ in $\mathrm{N}_{2}$ ) were fed to the reactor until the outlet peaks were constant. Non-chemisorbed $\mathrm{CO}$ was quantitatively transformed into $\mathrm{CH}_{4}$ over a $\mathrm{Ni} /$ Kieselgur catalyst and detected in a flame ionization detector connected on-line. The metal dispersion was calculated on the assumption of adsorption stoichiometry of $\mathrm{CO}$ to either Pd or Ni equal to 1 molecule of $\mathrm{CO}$ per atom of exposed metal. ${ }^{9}$

Transmission electron microscopy (TEM) experiments were carried out in a JEOL 100 CX II operated at $100 \mathrm{kV}$. Samples were dispersed in ethanol by sonication and dropped on a copper grid coated with carbon film.

\section{Catalytic evaluation of catalysts}

The hydrogenation reaction of styrene to ethylbenzene was performed in batch mode using a PTFE coated, stainless steel, stirred tank reactor. The reaction of styrene hydrogenation was performed at $333 \mathrm{~K}, 20$ bar hydrogen pressure, $1200 \mathrm{rpm}$ stirring rate, $0.3 \mathrm{~g}$ catalyst mass and $200 \mathrm{~mL}$ solution of $5 \%(\mathrm{v} / \mathrm{v})$ of styrene in toluene, $\mathrm{n}$-decane was used as an internal standard for chromatography analysis. Some tests were performed with the feed of the standard test additivated with $600 \mathrm{ppm}$ of thiophene, in order to assess the catalysts resistance to sulfur poisoning. Reactants and products were analyzed in a Shimadzu gas chromatograph equipped with a flame ionization detector and a 30 m, J\&W InnoWax capillary column (cat. number 19091N-213).

\section{RESULTS AND DISCUSSION}

\section{Catalysts characterization}

Table 1 contains the catalyst notation used and chemical composition of the catalysts. Mass concentration values were determined by ICP. The results indicate that total Pd and Ni load were established at 0.8 and 3.7 mass percent for all the prepared catalysts, the error of the technique was $\pm 13 \%$, with an atomic ratio of $\mathrm{Ni} / \mathrm{Pd} \cong 7.7$. The bulk atomic ratio of the bimetallic catalysts with both chlorine precursor were the highest ones.

Figures 1 and 2 show the XPS spectra of the samples in the Pd $3 \mathrm{~d}_{5 / 2}$ and $\mathrm{Ni} 2 \mathrm{p}_{3 / 2}$ region. The binding energies (BE) were determined by curve fitting of the spectrum line and they are tabulated in Table 2 .

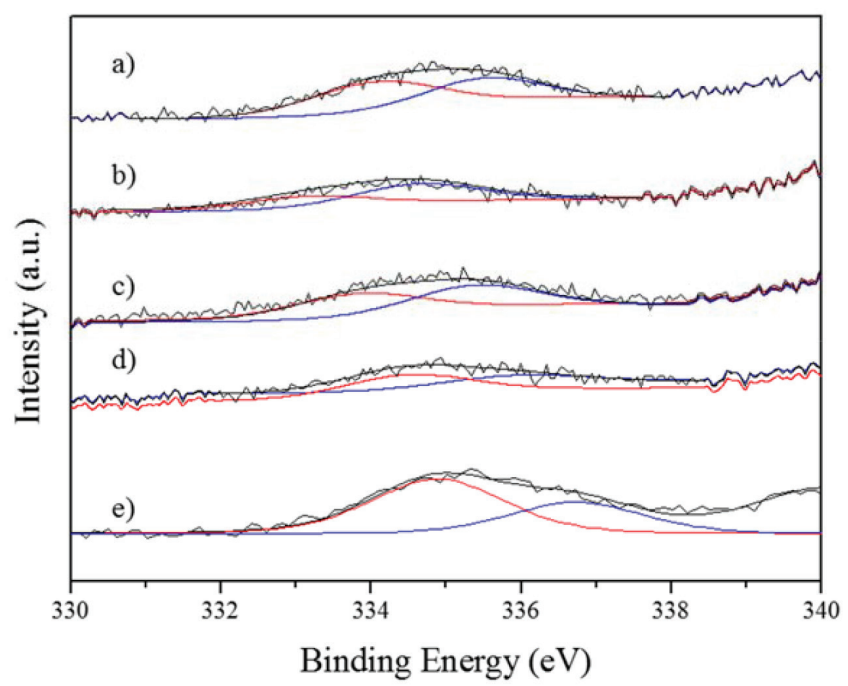

Figure 1. XPS spectra. Pd 3d $d_{5 / 2}$ region. a) NiClPd. b) PdNiN. c) NiNPd. d) PdNiCl. e) $P d$

As it can be seen in Figure 1 and Table 2 the catalysts had different surface Pd species. The peak located at about 334.1 - 334.8 $\mathrm{eV}$ was assigned to $\mathrm{Pd}^{0} .^{10} \mathrm{On}$ the monometallic catalyst and on some bimetallic ones also a peak at about $335.4-336.7 \mathrm{eV}$ can be seen that was attributed to the presence of electrodeficient chlorinated species of $\mathrm{Pd}^{\eta+}$ stabilized by the presence of remaining chlorine ions. These

Table 1. Names metal content (mass percentage) and bulk atomic ratio of the catalysts

\begin{tabular}{|c|c|c|c|c|c|c|}
\hline Catalyst & $1^{\text {st }}$ imp. & $2^{\text {nd }}$ imp. & $\operatorname{Pd}(\%)$ & $\mathrm{Ni}(\%)$ & $\mathrm{Cl}(\%)$ & $\mathrm{Cl} / \mathrm{Pd}$ \\
\hline$\overline{\mathrm{Pd}}$ & $\mathrm{PdCl}_{2}$ & - & 0.81 & & 0.91 & 3.4 \\
\hline NiClPd & $\mathrm{NiCl}_{2}$ & $\mathrm{PdCl}_{2}$ & 0.73 & 3.0 & 3.60 & 14.8 \\
\hline NiNPd & $\mathrm{Ni}\left(\mathrm{NO}_{3}\right)_{2} \cdot 6 \mathrm{H}_{2} \mathrm{O}$ & $\mathrm{PdCl}_{2}$ & 0.85 & 3.5 & 0.89 & 3.1 \\
\hline $\mathrm{PdNiCl}$ & $\mathrm{PdCl}_{2}$ & $\mathrm{NiCl}_{2}$ & 0.77 & 3.3 & 4.30 & 16.7 \\
\hline PdNiN & $\mathrm{PdCl}_{2}$ & $\mathrm{Ni}\left(\mathrm{NO}_{3}\right)_{2} \cdot 6 \mathrm{H}_{2} \mathrm{O}$ & 0.84 & 4.1 & 0.92 & 3.3 \\
\hline
\end{tabular}




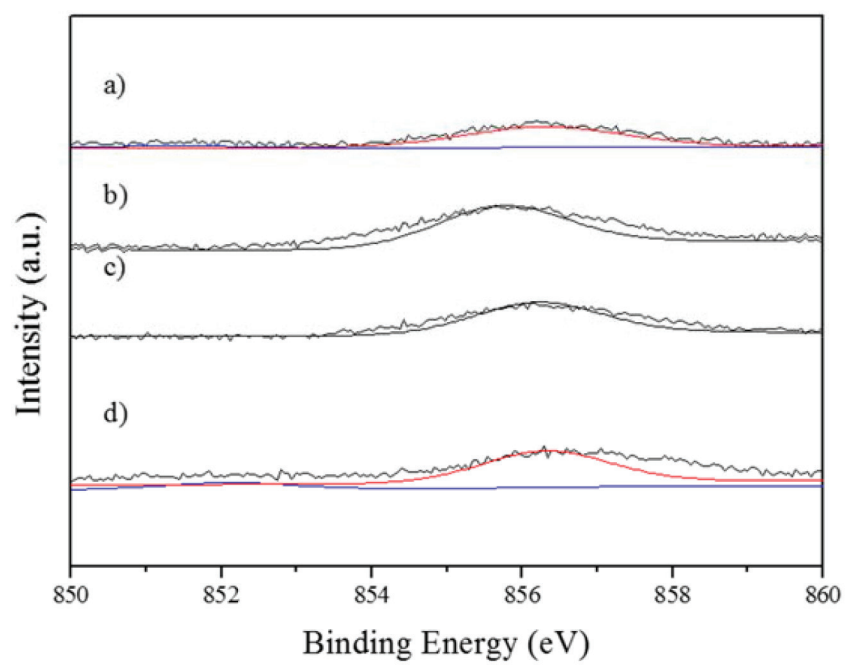

Figure 2. XPS spectra. Ni $2 p_{3 / 2}$ region. a) NiClPd. b) PdNiN. c) NiNPd. d) $\mathrm{PdNiCl}$

species would have the formula, $\mathrm{Pd}^{\eta+} \mathrm{Cl}_{\mathrm{x}} \mathrm{O}_{\mathrm{y}}$ with $0<\eta<2 .{ }^{6}$ The bimetallic PdNiN and NiNPd catalysts had a peak at $333.5 \pm 0.3 \mathrm{eV}$ that according to some reports would have a higher availability of electrons, i.e. they would be species $\mathrm{Pd}^{-}$(with $\delta<0$ ). These species could be due to the formation of metal bonds or alloys. ${ }^{11,12}$

When the region of $\mathrm{Ni}$ binding energies of the bimetallic $\mathrm{PdNiCl}$ and $\mathrm{NiClPd}$ catalysts is analyzed (Figure 2 and Table 2) a peak at about $851.7 \pm 0.4 \mathrm{eV}$ can be seen that would correspond to $\mathrm{Ni}^{0} .{ }^{10}$ The peak at $856.0 \pm 0.4 \mathrm{eV}$ in all bimetallic catalysts would correspond to the presence of nickel oxide $\left(\mathrm{Ni}^{+2}\right)$ that according with literature reports would have a strong interaction with the alumina support. ${ }^{10,13,14}$ Some authors suggested the presence of $\mathrm{NiO} \cdot \mathrm{x}\left(\mathrm{Al}_{2} \mathrm{O}_{3}\right)(0 \leq \mathrm{x} \leq 1)$ species that would be formed during the thermal treatments. ${ }^{15}$

With respect to the atomic ratios obtained by XPS (Table 2) similar values were obtained in the case of the $\mathrm{Pd} / \mathrm{Al}$ ratio. All XPS spectra had a peak at $198.5 \mathrm{eV}$ corresponding to $\mathrm{Cl} 2 \mathrm{p}_{3 / 2}$ that could be due to surface chlorine species that were not eliminated during the thermal pretreatment stages. ${ }^{10} \mathrm{PdNiCl}$ and NiClPd catalysts had high $\mathrm{Cl} / \mathrm{Pd}$ ratios because these catalysts were impregnated with chlorine-containing metal precursors. The Ni/Pd ratios are higher for the PdNiN and $\mathrm{PdNiCl}$ catalysts. This would be related to the preparation procedure because $\mathrm{Ni}$ is impregnated in second place, thus staying in an outer position. ${ }^{7}$

The metal dispersion of the catalysts depends strongly on the chemical nature of the precursors and on the thermal treatments the catalysts underwent. As seen in Table 2 the monometallic catalyst was the one with higher metal dispersion. The lower dispersion and hence the higher particle size of the bimetallic catalysts could be related to the double thermal treatment they were exposed to.
This long thermal treatment would cause more sintering of Pd and Ni particles. ${ }^{16}$ Bimetallic catalysts with $\mathrm{Ni}$ as a precursor chlorine had higher dispersion than the bimetallic ones with Ni nitrate as precursor. This could be related to the presence of complex species of the $\mathrm{Pd}^{\eta+} \mathrm{Cl}_{\mathrm{x}} \mathrm{O}_{\mathrm{y}}$ kind, formed during the calcination treatment. The smaller particle size is related to a high dispersion and a higher value of binding energy (BE). ${ }^{17,18}$ The monometallic Pd catalyst would have the smallest particles and the bimetallic catalysts prepared from $\mathrm{Ni}$ nitrate (NiNPd and PdNiN) would have the bigger particles.

The size of the palladium cristallites was affected by the addition of Ni to the bimetallic catalysts. The growth pattern of palladium cristallites in the presence of $\mathrm{Ni}$ has been previously explained by the Pd-Ni competition for the support sites during catalyst preparation. ${ }^{19}$

The X-ray diffractograms of all catalysts had only three peaks at $2 \theta=37.7^{\circ}, 46.0^{\circ}(400)$ and $67.0^{\circ}$ (440), corresponding to the structure of $\gamma-\mathrm{Al}_{2} \mathrm{O}_{3} \cdot{ }^{20}$ For this reason the difractograms are not presented. No peak at $39.7^{\circ}$, related to the (111) reflections of $\mathrm{Pd}^{021}$ could be found, neither the peaks corresponding to the $\mathrm{PdO}$ or the peaks due to bulk NiO. This was attributed to the small particle size and the relatively high limit of detection of the XRD technique. ${ }^{22}$ Heracleous et $a l .{ }^{23}$ have reported that in catalysts of Ni supported over alumina, a minimum $\mathrm{Ni}$ mass content of $15 \%$ is needed in order to detect the $\mathrm{NiO}$ (bulk) diffraction lines at $2 \theta=43.3^{\circ}, 63.0^{\circ}$, $75.5^{\circ}$ and $79.5^{\circ}$. Salagre et al..$^{24}$ have reported that the low intensity diffraction lines of $\mathrm{NiO}$ particles of $\mathrm{Ni} / \mathrm{Al}_{2} \mathrm{O}_{3}$ catalysts would only be detected at $\mathrm{Ni}$ contents higher than $26.6 \%$. In our case, due to this low sensitivity of the XRD method the $\mathrm{Pd}$ and $\mathrm{NiO}$ phases cannot be detected.

Figure 3 shows the TPR traces of the catalysts. These tests were performed in order to determine the reducibility of the $\mathrm{Pd}$ and $\mathrm{Ni}$ species on the surface of alumina.

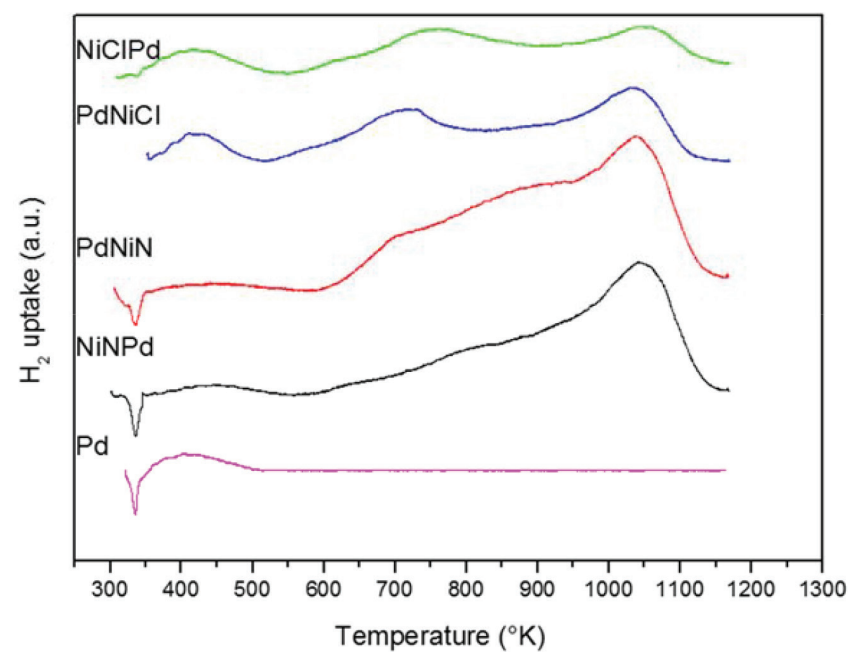

Figure 3. $T P R-H_{2}$ traces

Table 2. Metal dispersion as determined by CO chemisorption and binding energies of Pd and Ni species as determined by XPS

\begin{tabular}{|c|c|c|c|c|c|c|c|c|c|}
\hline \multirow[t]{2}{*}{ Catalysts } & \multirow[t]{2}{*}{$\mathrm{D}(\%)$} & \multicolumn{3}{|c|}{$\begin{array}{l}\mathrm{Pd} 3 d_{5 / 2} \\
\operatorname{BE}(e V)\end{array}$} & \multicolumn{2}{|c|}{$\begin{array}{l}\mathrm{Ni} 2 \mathrm{p}_{3 / 2} \\
\mathrm{BE}(\mathrm{eV})\end{array}$} & \multicolumn{3}{|c|}{$\begin{array}{l}\text { Atomic Ratios } \\
\text { (at/at) }\end{array}$} \\
\hline & & $\mathrm{Pd}^{\delta-}$ & $\mathrm{Pd}^{0}$ & $\mathrm{Pd}^{\eta+}$ & $\mathrm{Ni}^{0}$ & $\mathrm{NiO} \cdot \mathrm{xAl}_{2} \mathrm{O}_{3}$ & $\mathrm{Cl} / \mathrm{Pd}$ & $\mathrm{Ni} / \mathrm{Pd}$ & $\mathrm{Pd} / \mathrm{Al}$ \\
\hline $\mathrm{Pd}$ & 38.2 & & $334.8^{(63 \%)}$ & $336.7^{(37 \%)}$ & & & 1.12 & & 0.0025 \\
\hline $\mathrm{PdNiCl}$ & 28.6 & & $334.5^{(73 \%)}$ & $336.0^{(27 \%)}$ & $852.1^{(19 \%)}$ & $856.3^{(82 \%)}$ & 6.77 & 9.38 & 0.0016 \\
\hline NiClPd & 33.5 & & $334.1^{(58 \%)}$ & $335.5^{(42 \%)}$ & $851.4^{(7 \%)}$ & $856.3^{(93 \%)}$ & 5.22 & 5.90 & 0.0021 \\
\hline PdNiN & 13.2 & $333.2^{(40 \%)}$ & $334.6^{(60 \%)}$ & & & 855.6 & 4.75 & 9.96 & 0.0021 \\
\hline NiNPd & 14.1 & $333.8^{(47 \%)}$ & & $335.4^{(53 \%)}$ & & 856.2 & 4.54 & 6.88 & 0.0025 \\
\hline
\end{tabular}




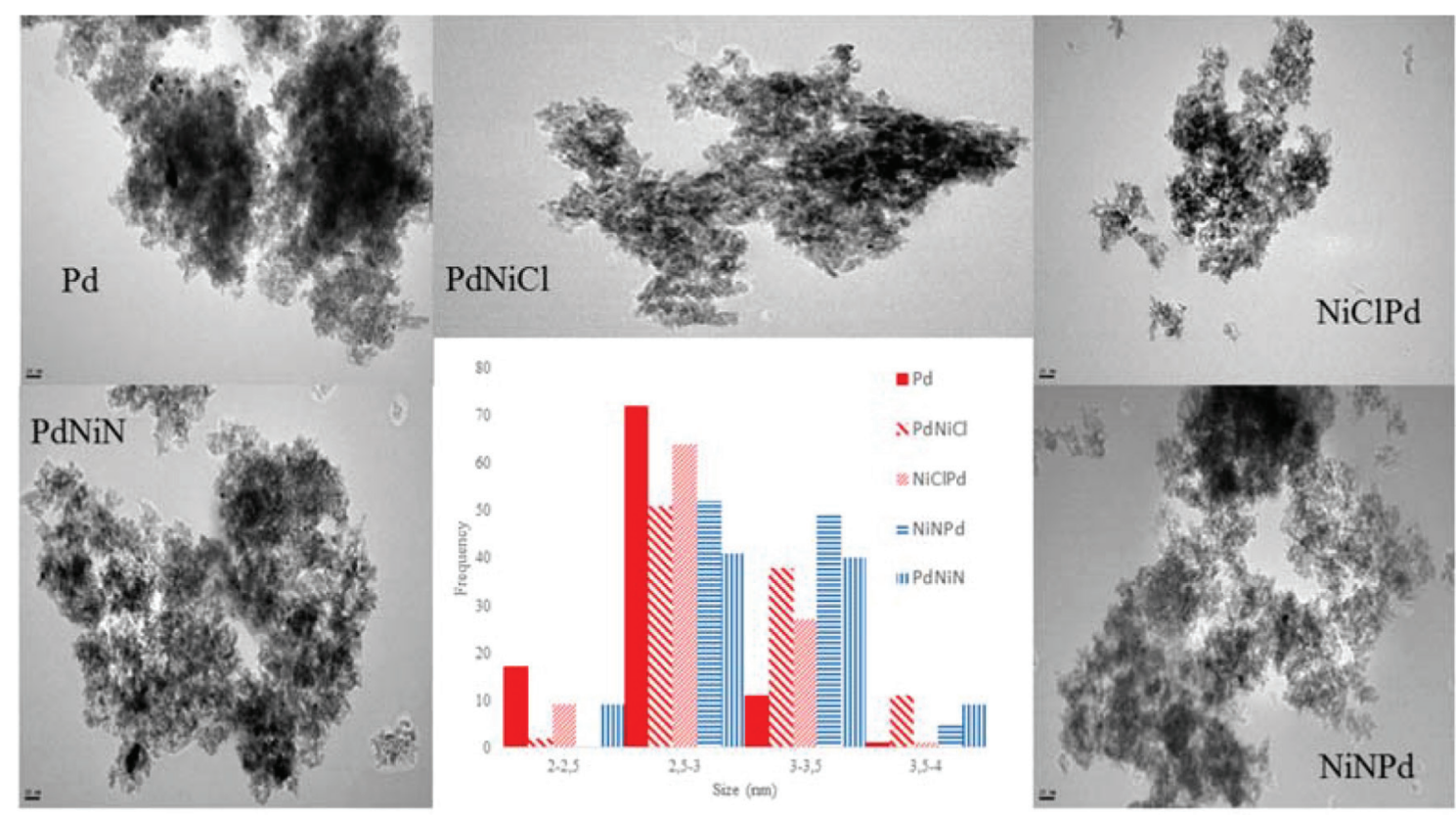

Figure 4. TEM results. Micrographs and size distribution plot

The Pd monometallic catalyst (Pd) and the bimetallic PdNi of nitrate precursor (PdNiN and NiNPd) had a negative peak at low temperature, about $343 \mathrm{~K}$, which is attributed to the decomposition of the $\mathrm{Pd} \beta$-hydride phase..$^{25} \mathrm{The} \beta$-PdH phase is not seen in the bimetallic catalysts with chlorinated precursor ( $\mathrm{PdNiCl}$ and $\mathrm{NiClPd}$ ) due to the excessive presence of chlorine that would prevent the formation of this phase. What is seen in the two latter ones is a broad peak between 373 and $473 \mathrm{~K}$ that could be assigned according to some authors, to the reduction of $\mathrm{PdO}$ species strongly interacting with the support. Other authors suggest that the consumption of hydrogen near these temperatures is due to the reduction of $\mathrm{Pd}^{\eta+} \mathrm{Cl}_{\mathrm{x}} \mathrm{O}_{\mathrm{y}}(0<\eta<2)$ species or to the reduction of $\mathrm{Pd}^{+2}$ ions stabilized by neighbouring $\mathrm{Cl}^{-}$, that were not eliminated during calcination and remain on the alumina surface. ${ }^{26-28}$

Figure 3 shows that above $503 \mathrm{~K}$ multiple hydrogen consumption peaks appear due to the reduction of $\mathrm{NiO}$ species that interact with the support. The first peaks at 520-620 can be assigned to the reduction of $\mathrm{NiO}_{x}$ with weak or null interaction with the support (bulk NiO). ${ }^{19,29-32}$ Reduction peaks at higher temperatures in the $620-770 \mathrm{~K}$ and 773-1073 K range, are attributed to the reduction of well dispersed $\mathrm{NiO}$, interacting strongly with the support, and in the range 1000$1273 \mathrm{~K}$ to the reduction of the $\mathrm{NiAl}_{2} \mathrm{O}_{4}$ spinel. ${ }^{29,31,32}$ In the case of the bimetallic catalysts prepared from nickel chloride salts $(\mathrm{PdNiCl}$ and NiClPd) a well defined TPR peak corresponding to bulk NiO in the temperature range 623-773 $\mathrm{K}$ can be seen. In the case of the bimetallic catalysts prepared from nitrate salt (PdNiN and NiNPd) a bigger presence of $\mathrm{NiO}$ interacting strongly with the support is seen. The higher chlorine content would prevent a strong interaction of $\mathrm{Ni}$ with alumina. For all prepared catalysts the peak at temperatures higher than $1000 \mathrm{~K}$ would correspond to the presence of nickel refractory species, $\mathrm{NiAl}_{2} \mathrm{O}_{4}$.

According to the reduction temperature employed during the synthesis of the catalysts ( $1 \mathrm{~h}$ at 673 in a hydrogen stream), bimetallic catalysts prepared with chloride salt ( $\mathrm{PdNiCl}$ and $\mathrm{NiClPd})$ would be at least in part reduced as $\mathrm{Pd}^{0}$ and $\mathrm{Ni}^{0}$. This would coincide with the XPS information because both bimetallic catalysts had $\mathrm{Pd}^{0}$ and $\mathrm{Ni}^{0}$. While bimetallic prepared from nitrate salt (PdNiN and NiNPd) will present $\beta$-PdH phase and $\mathrm{NiO}_{x}$ surface species interacting with support. These results were corroborated by XPS.
TEM micrographs of the catalysts are shown in Figure 4. Small spherical Pd particles with diameters in the range of $2-3.5 \mathrm{~nm}$ can be seen in the case of the monometallic catalyst. For all bimetallic catalysts an increase of the size was detected (2.5-4 nm) while the size distribution was less homogeneous. This would point to a higher dispersion of the monometallic catalyst.

\section{Catalytic Test}

In all the performed catalytic tests the selectivity to ethylbenzene was higher than $98 \%$. Figure 5 shows values of total conversion as a function of time for the reaction with thiophene-free feed.

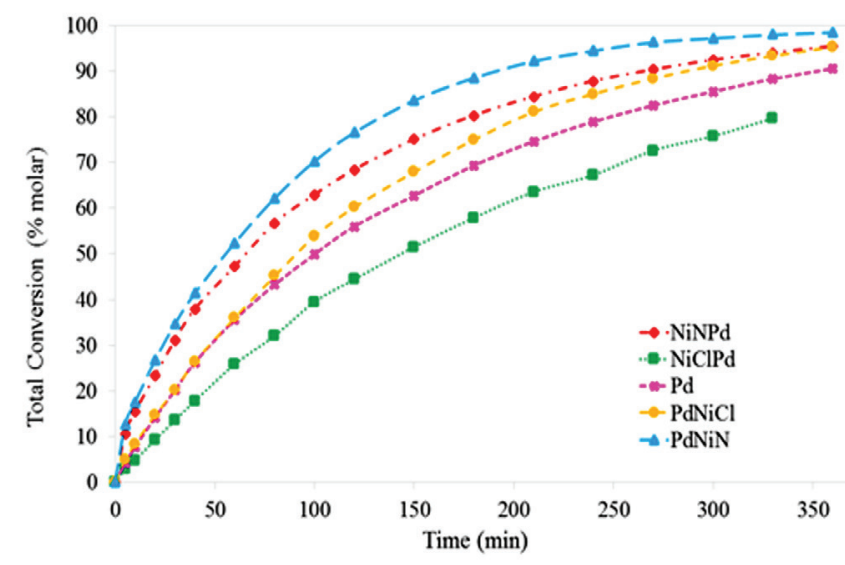

Figure 5. Total conversion of styrene as a function of time. Tests with thiophene-free feed

It can be seen that PdNiN and NiNPd were the most active materials, with conversion values higher than $90 \%$, for reaction time values of $300 \mathrm{~min}$. The ordering of the catalysts according to their activity was: $\mathrm{PdNiN}>\mathrm{NiNPd}>\mathrm{PdNiCl}>\mathrm{Pd}>\mathrm{NiClPd}$. During the reaction of hydrogenation the dissociative adsorption of the $\mathrm{H}-\mathrm{H}$ bond is favored by the interaction of the $\boldsymbol{d}$ orbitals of the metals rich in electrons with the antibonding molecular orbitals of hydrogen. ${ }^{33}$ The high conversion values of PdNiN and NiNPd could be due to 
the presence of $\mathrm{Pd}^{\delta-}$ with a higher availability of electrons (lower $\mathrm{BE})$. The most active catalyst is $\mathrm{PdNiN}$ that has both $\mathrm{Pd}^{\delta-}$ and $\mathrm{Pd}^{0}$ species, both with $\boldsymbol{d}^{10}$ orbitals that favor the dissociative adsorption of hydrogen. The most active of the bimetallic catalysts with chlorinated nickel precursor is $\mathrm{PdNiCl}$, that has a high concentration of metallic palladium and has also metallic nickel $\left(\boldsymbol{d}^{10}\right.$ and $\left.\boldsymbol{d}^{8}\right)$. Both favor the dissociative adsorption of hydrogen.

The results of the tests with a sulfur doped feed can be seen in Figure 6. All catalysts show a decrease of the total conversion as a consequence of the loss of active sites. However no big differences between the different catalysts can be seen.

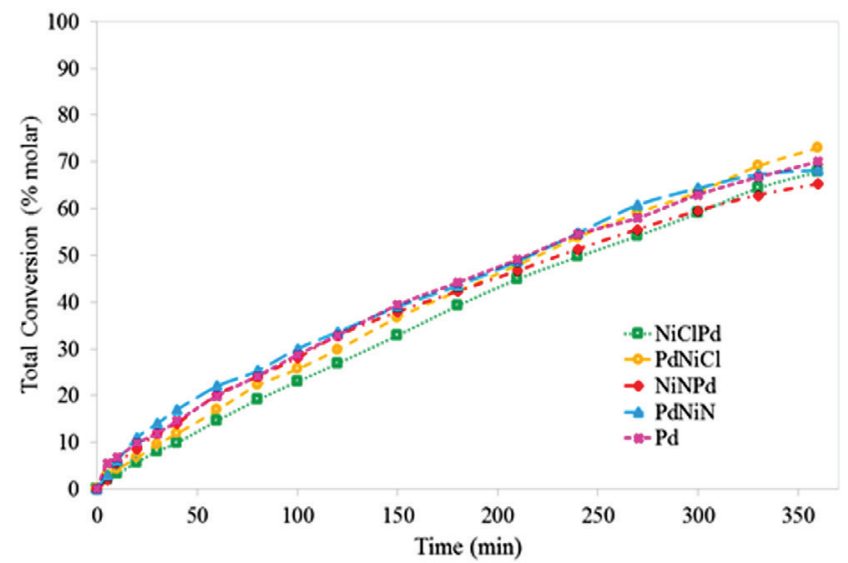

Figure 6. Total conversion of styrene as a function of time. Feed poisoned with thiophene

The resistance to sulfur poisoing was assessed by calculating the initial reaction rates for the reactions sulfur free $\left(\mathrm{r}_{\mathrm{sf}}^{\mathrm{o}}\right)$ and sulfur poisoned $\left(\mathrm{r}_{\mathrm{sp}}^{\mathrm{o}}\right)$. From the values of initial reaction rate and considering a simple model of linear deactivation (zero order deactivation), the fraction of poisoned sites $(\alpha)$ can be calculated as $\alpha=1-\mathrm{r}_{\mathrm{sp}}^{\mathrm{o}} / \mathrm{r}_{\mathrm{sf}}^{\mathrm{o}}$. Table 3 shows values of initial values of hydrogenation and fraction of poisoned sites $(\alpha)$. The found order of activity of the tests without poison was: $\mathrm{PdNiN}>\mathrm{NiNPd}>\mathrm{PdNiCl} \geq \mathrm{Pd}>>\mathrm{NiClPd}$. In the presence of thiophene the found activity order was: $\mathrm{PdNiN}>\mathrm{NiNPd} \geq$ $\mathrm{Pd}>\mathrm{PdNiCl}>>\mathrm{NiClPd}$. The order of the catalysts with respect to poisoning resistance was: $\mathrm{PdNiN} \cong \mathrm{NiNPd}<<\mathrm{PdNiCl}<\mathrm{Pd}<\mathrm{NiClPd}$.

Table 3. Initial hydrogenation rates and fraction of poisoned sites $(\alpha)$

\begin{tabular}{lccc}
\hline Catalysts & $\begin{array}{c}\mathrm{r}_{\mathrm{sf}}^{\mathrm{o}} \\
{\left[\mathrm{mol} \mathrm{mL}^{-1} \mathrm{~min}^{-1}\right]}\end{array}$ & $\begin{array}{c}\mathrm{r}_{\mathrm{sp}}^{\mathrm{o}} \\
{\left[\mathrm{mol} \mathrm{mL}^{-1} \mathrm{~min}^{-1}\right]}\end{array}$ & $\alpha$ \\
\hline $\mathrm{Pd}$ & $0.23 \pm 0.01$ & $0.11 \pm 0.01$ & 0.51 \\
$\mathrm{PdNiCl}$ & $0.24 \pm 0.02$ & $0.10 \pm 0.02$ & 0.57 \\
$\mathrm{NiClPd}$ & $0.16 \pm 0.02$ & $0.09 \pm 0.02$ & 0.45 \\
PdNiN & $0.46 \pm 0.02$ & $0.13 \pm 0.01$ & 0.72 \\
NiNPd & $0.41 \pm 0.01$ & $0.12 \pm 0.01$ & 0.71 \\
\hline
\end{tabular}

According to the most accepted model for the sulfur poisoning of Group VIII metals, poisoning occurs by a donation of electrons from the metal (Lewis basic site) to the sulfur atom (Lewis acid site) ${ }^{6}$ As seen in Table 3 the NiClPd catalyst has the lowest fraction of poisoned sites. Its high thioresistance would be due to the presence of $\mathrm{Pd}^{\eta+} \mathrm{O}_{\mathrm{x}} \mathrm{Cl}_{\mathrm{y}}$ and $\mathrm{NiO} \cdot \mathrm{xAl}_{2} \mathrm{O}_{3}$ species that prevent the adsorption of thiophene either by steric hindrance and/or electronic effects (on $\mathrm{Pd}^{\eta+}$ and $\mathrm{Ni}^{2+}$, Lewis acid sites). Besides the lower thioresistance of PdNiN and NiNPd would be related to the amount of exposed $\mathrm{Pd}^{\delta-}$ species (Lewis basic sites) that promote a strong adsorption of the poison and thus an increase of the blocking of active sties. This would be due to the mentioned poisoning mechanism of Group VIII metals, i.e. electron donation from the metal to sulfur. Particularly thiophene would interact with the metal surface in a planar way through the electrons of the aromatic ring (weak $\eta_{5}$ bond) ${ }^{6,7,34}$ In the case of the test reactions with thiophene some of the $\boldsymbol{d}$ electrons of Pd would be shared with sulfur atoms, thus decreasing the activity of the catalysts.

Taking into account the chlorine present on the catalysts as detailed in Table 1 some other conclusions can be reached. Of the 4 bimetallic catalysts the two catalysts prepared with nitrate salt, PdNiN and NiNPd, were the least sulfur resistant. Both had a lower $\mathrm{Cl} / \mathrm{Pd}$ surface ratio in comparison to the bimetallic catalysts prepared with a Ni chloride salt, NiClPd and $\mathrm{PdNiCl}$. The presence of remaining chlorine would be a determining factor on the resistant to sulfided compounds and other poisons.

In the case of the bimetallic catalysts prepared with $\mathrm{Ni}$ chloride, $\mathrm{NiClPd}$ and $\mathrm{PdNiCl}$, it can be seen that the most thioresistant is NiClPd. This has a lower percentage of surface $\mathrm{Pd}^{0}$ and $\mathrm{Ni}^{0}$ in comparison to the $\mathrm{PdNiCl}$ catalyst. Both species, $\mathrm{Pd}^{0}$ and $\mathrm{Ni}^{0}$, are prone to be poisoned because of their higher availability of electrons.

\section{CONCLUSIONS}

The effect of the sequence of impregnation and of the kind of palladium and nickel precursor used was evaluated for a series of bimetallic Pd-Ni catalysts. The properties assessed were the catalytic activity and the sulfur resistance, during the selective hydrogenation of styrene. Excepting NiClPd, all the bimetallic catalysts were found to be more active than the Pd monometallic catalyst.

The XPS results point to the presence of different $\mathrm{Pd}^{\delta}, \mathrm{Pd}^{0}$ and $\mathrm{Pd}^{n+} \mathrm{O}_{\mathrm{x}} \mathrm{Cl}_{\mathrm{y}}$ species. The presence of $\mathrm{Pd}^{\delta-}$ species would indicate the formation of a metallic bond or a Pd-Ni alloy. Species of Pd with high availability of electrons were found on the bimetallic catalysts suggesting that an electronic effect would be partly responsible for their higher conversion of styrene, either in the presence or the absence of thiophene. The order of hydrogenation rate of styrene in the absence of sulfur was: $\mathrm{PdNiN}>\mathrm{NiNPd}>\mathrm{PdNiCl} \geq \mathrm{Pd}>>\mathrm{NiClPd}$. After the poisoning with $600 \mathrm{ppm}$ thiophene the order changed to: $\mathrm{PdNiN}>\mathrm{NiNPd} \geq \mathrm{Pd}>\mathrm{PdNiCl}>>\mathrm{NiClPd}$. The bimetallic catalysts prepared by successive impregnation of $\mathrm{NiCl}_{2}$ and $\mathrm{PdCl}_{2}$ had a high surface content of chlorine. These catalysts were the most sulfur resistant because of steric and electronic effects. The great poisoning of PdNiN and NiNPd bimetallic catalysts would be due to the easy adsorption of the thiophene sulfur atoms over the relatively abundant $\mathrm{Pd}^{\delta-}$ species with high availability of electrons.

Bimetallic PdNiN and NiNPd catalysts were the most active during hydrogenation of styrene in the absence of thiophene. A higher concentration of surface $\mathrm{Pd}^{\delta-}$ species on these catalysts would be responsible for the higher activity. $\mathrm{PdNiCl}$ and $\mathrm{NiClPd}$ had the highest $\mathrm{Cl} / \mathrm{Pd}$ ratios and were also the most thioresistant. Oxychlorinated $\mathrm{Pd}$ species $\left(\mathrm{Pd}^{\eta+}\right)$ probably prevented the adsorption of thiophene by means of steric hindrance (big size of Pd oxychloride species) and electronic effects (high electronegativity of $\mathrm{Cl}$ ). NiClPd was the more sulfur resistant than $\mathrm{PdNiCl}$. This could be due to a lower percentage of $\mathrm{Pd}^{0}$ and $\mathrm{Ni}^{0}$ in comparison to $\mathrm{PdNiCl}$, since both species $\left(\mathrm{Pd}^{0}\right.$ and $\mathrm{Ni}^{\circ}$ ) are more prone to be poisoned due to their higher electronic availability.

\section{ACKNOWLEDGEMENTS}

We thank CONICET, ANPCyT and UNL for the financial assistance of this work (Grants PIP 112-201101-00410 and 112201301-00457, PICT and CAI + D). 


\section{REFERENCES}

1. Hatch, L. F.; Matar, S.; From Hydrocarbon to Petrochemicals, Gulf Publishing Company: Houston, 1981, ch. 3 and 7.

2. Zhou, Z.; Zeng, T.; Cheng Z.; Yuan, W.; Chem. Eng. Sci. 2010, 65, 1832.

3. Nijhuis, T. A.: Dautzenberg, F. M.; Moulijn, J. A.; Chem. Eng. Sci. 2003, $58,1113$.

4. Gaspar, A. B.; dos Santos, G. R.; de Souza Costa, R.; da Silva, M. A. P.; Catal. Today 2008, 133-135, 400.

5. Choi, J. S.; Mauge, F.; Pichon, C.; Fourcade, J. O.; Jumas, J. C.; Clair, C. P.; Uzio, D.; Appl. Catal., A 2004, 267, 203.

6. Badano, J.; Quiroga, M.; Betti, C.; Vera, C.; Canavese, S.; ColomaPascual, F.; Catal. Lett. 2010, 137, 35.

7. Betti, C.; Badano, J. M.; Maccarrone, M. J.; Mazzieri, V.; Vera, C.; Quiroga, M.; App. Catal., A 2012, 181-186, 435.

8. Betti, C.; Badano; J.; Rivas, I.; Mazzieri, V.; Maccarrone, M. J.; Vera, C.; Quiroga, M.; J. Chem. 2012, 8, 1.

9. Chen, H.; Li, T.; Jiang, F.; Wang, Z.; J. Mol. Catal. A: Chem. 2016, 421, 167.

10. NIST, X-ray Photoelectron Spectroscopy Database NIST Standard Reference Database 20, Version 3.5 (Web Version), National Institute of Standards and Technology, USA, 2007.

11. Park, K. W.; Choi, J. H.; Sung, Y. E.; J. Phys. Chem. B 2003, 107, 5851.

12. Abu Bakar, N. H. H.; Bettahar, M. M.; Abu Bakar, M.; Monteverdi, S.; Ismail. J.; Alnot, M.; J. Catal. 2009, 265, 63.

13. Wagner, C. D.; Riggs, W. M.; Davis, R. D.; Moulder, J. F.; Muilenberg, G. E.; Handbook of X-ray Photoelectron Spectroscopy Perkin-Elmer Corp., Physical Electronics Division, Eden Prairie, Minnesota, USA, 1979.

14. Castaño, P.; Pawelec, B.; Fierro, J. L. G.; Arandes, J. M.; Bilbao, J.; Fuel 2007, 86, 2262.

15. Salagre, P.; Fierro, J. L. G.; Medina, F.; Sueiras, J. E.; J. Mol. Catal. A: Chem. 1996, 106, 125.

16. Ivanova, A. S.; Slavinskaya, E. M.; Gulyaev, R. V.; Zaikovskii, V. I.; Stonkus, O. A.; Danilova, L. G.; Plyasova, L. M.; Polukhina, I. A.; Boronin, A. I.; Appl. Catal., B 2010, 97, 57.
17. Voogt, E. H.; Mens, A. J. M.; Gijzeman, O. L. J.; Geus, J. W.; Surf. Sci. 1996, 350, 21.

18. Beketov, G.; Heinrichs, B.; Pirard, J. P.; Chenakin, S.; Kruse, N.; Appl. Surf. Sci. 2013, 287, 293.

19. Hilli, Y.; Kinnunen, N. M.; Suvanto, M.; Savomaki, A.; Kallinen, K.; Pakkanen, T. A.; Appl. Catal., A 2015, 497, 85.

20. Huang, S.; Zhang, C.; He, H.; Catal. Today 2008. 139, 15.

21. Cobo, M.; Quintero, A.; Montes de Correa, C.; Catal. Today 2008, 133 135,509

22. Telkar, M. M.; Nadgeri, J. M.; Rode, C. V.; Chaudhari, R. V.; Appl. Catal., A 2005, 295, 23.

23. Heracleous, E.; Lee, A. F.; Wilson, K.; Lemonidou, A. A.; J. Catal. 2005, 231,159

24. Salagre, P.; Fierro, J. L. G.; Medina, F.; Sueiras, J. E.; J. Mol. Catal. A: Chem. 1996, 106, 125.

25. Sá, J.; Arteaga, G. D.; Daley, R. A.; Bernardi, J.; Anderson, J. A.; J. Phys. Chem. B 2006, 110, 17090.

26. Sales, E. A.; Jove, J.; De Jesús Mendez, M.; Bozon-Verduraz, F.; J. Catal. 2000, 195, 88 .

27. Noronha, F. B.; Aranda, D. A. G.; Ordine, A. P.; Smachl, M.; Catal. Today 2000, 57, 275.

28. Pinna, F.; Menegazzo, F.; Signoretto, M.; Canton, P.; Fagherazzi, G.; Pernicone, N.; Appl. Catal., A 2001, 219, 195.

29. Kim, P.; Kim, H.; Joo, J. B.; Kim, W.; Song, I: K.; Yi, J.; J. Mol. Catal. A: Chem. 2006, 256, 178.

30. Hoffer, B. W.; Dick van Langeveld, A.; Janssens, J. P.; Bonne, R. L. C.; Lok, C. M.; Moulijn, J. A.; J. Catal. 2000, 192, 432.

31. Juan-Juan, J.; Roman-Martinez, M. C.; Illan-Gomez, M. J.; Appl. Catal., A 2006, 301, 9.

32. Hou, Z.; Yokota, O.; Tanaka, T.; Yashima, T.; Appl. Catal., A 2003, 253, 381.

33. Shriver, D. F.; Atkins, P. W.; Langford, C. H.; Inorganic Chemistry, $3^{\text {rd }}$ ed., WH Freeman and Co: New York, 1994, p. 258.

34. Arcoya, A.; Seoane, X. L.; Gomez-Sainero, L. M.; Appl. Surf. Sci. 2003 , 211,341 